\title{
A crítica ao paradigma culturalista na interpretação da formação histórica brasileira
}

The critique to the culturalist paradigm in the interpretation of the historical formation of Brazil

\section{Renato Somberg Pfeffer ${ }^{1}$}

Resumo: A formação histórica brasileira tem sido estudada a partir da influência, direta ou indireta, de um arcabouço weberiano. Essa matriz teórica assume a ideia de que a estrutura política brasileira não conseguiu superar a cultura política patrimonialista de origem portuguesa. O motivo disso seria uma peculiar articulação entre o autoritarismo social com a acumulação capitalista que teria bloqueado a construção da cidadania no país. Além das divergências internas, essa vertente culturalista tem sido questionada por suas limitações e incongruências. O presente texto pretende discutir teoricamente as críticas que o paradigma culturalista tem recebido e que explicitam as fragilidades analíticas desse modelo que busca situar e explicar o Brasil como país periférico marcado pelo amálgama da dominação tradicional/racional e associaram o atraso em relação ao centro capitalista com a herança patrimonialista ibérica.

Palavras-chave: Formação histórica brasileira; Paradigma culturalista; Patrimonialismo; Fragilidade das interpretações culturalistas.

Abstract: Brazilian historical formation has been studied from the direct or indirect influence of a Weberian framework. This theoretical matrix assumes the idea that the Brazilian political structure has not succeeded in overcoming the political patrimonialist culture of Portuguese origin. The reason for this would be a peculiar articulation between social authoritarianism and capitalist accumulation that would have blocked the construction of citizenship in the country. In addition to internal divergences, this culturalist aspect has been questioned by its limitations and incongruities. This paper intends to discuss theoretically critiques that the culturalist paradigm has received and that explain the analytical weaknesses of this model that seeks to situate and explain Brazil as a peripheral

\footnotetext{
${ }^{1}$ Doutor em Filosofia pela Universidade Complutense de Madri. Mestre em Sociologia pela UFMG. Pós graduado em História do Brasil pela Pucminas. Graduado em Comunicação pela UFMG e História pela FAFIBH. Pesquisador e professor da Fundação João Pinheiro de Minas Gerais. E-mail: renato.pfeffer@fjp.mg.gov.br
} 
country marked by the amalgam of traditional / rational domination and associated the delay in relation to the capitalist center with the Iberian patrimonial heritage.

Key words: historical formation of Brazil; Culturalist paradigm; Patrimonialism; Fragility of culturalist interpretations.

\section{Introdução}

A formação histórica brasileira no que tange à interpretação dos motivos que impedem a superação do patrimonialismo ibérico tem sido estudada por diversos autores contemporâneos a partir da influência, direta ou indireta, de um arcabouço teórico weberiano (IAMAMOTO, 2006; BEHRING; BOSCHETTI, 2007; YAZBEK, 1993; PAULA, 2005, entre outros). Esses trabalhos são orientados pela percepção de que a cultura política de uma determinada sociedade resulta de orientações cognitivas, emocionais e valorativas que se padronizam ao longo do tempo. Nesse sentido, as normas, valores e instituições da comunidade constituem sua cultura (BAQUERO, 2001).

$\mathrm{Na}$ análise de Ianamoto (2006), assim como para Behring e Boschetti (2007), a formação política do país se deu por relação de favores e pelos laços de dependência pessoal que aprofundavam a confusão entre o público e o privado. $\mathrm{O}$ comando desse processo coube a grupos privados que se apossaram do Estado para fazer valer seus interesses particulares. Yazbek (1993), por sua vez, aponta para o caráter moralista, autoritário e elitista da história brasileira que age com descaso nas questões de equidade e justiça na vida pública. O Brasil acaba se tornando um lugar onde a modernização é mediada pelo arcaico, numa recriação da herança escravista e patrimonialista impedindo, assim, o rompimento da formação histórica originária. Paula (2005) destaca a precariedade estrutural dos direitos sociais que seria uma consequência da debilidade, assimetria, heterogeneidade, incompletude e desigualdade do desenvolvimento brasileiro. Essa cultura precária seria o motivo fundamental para que os direitos sociais básicos não fossem contemplados por parcela significativa da população. Essa "contrarrevolução recorrente" (PAULA, 2005, p.17) seria garantida pelo Estado autoritário. Um Estado que, segundo Behring e Boschetti (2007), foi gestado em um contexto marcado pela ambiguidade entre o liberalismo formal que o funda e a prática patrimonialista que garantia privilégios às elites dominantes.

Os autores supracitados, de forma geral, assumem a ideia de que a estrutura política brasileira não conseguiu superar a cultura política patrimonialista. O motivo disso seria uma peculiar articulação entre o autoritarismo social com a acumulação capitalista que teria 
bloqueado a construção da cidadania no país. Tributária de uma corrente weberiana culturalista de interpretação da história do Brasil, essa vertente está associada a pensadores relevantes da sociologia brasileira entre os quais se destacam, entre outros, Gilberto Freyre (1990), Sérgio Buarque de Holanda (1976), Raymundo Faoro (1977), Simon Schwartzman (1998), Florestan Fernandes (1975) e Maria Silvia de Carvalho (1997). Esses autores possuem profundas controvérsias no que tange, principalmente, à interpretação da relação entre o Estado e sociedade ${ }^{2}$ : qual o peso de cada um desses polos? Qual o grau de convergência ou disjunção entre eles? Além das divergências internas, essa vertente culturalista fundada no conceito de patrimonialismo tem sido questionada. O presente texto pretende discutir teoricamente algumas críticas que o paradigma culturalista tem recebido.

\section{A crítica à vertente culturalista de intepretação do Brasil: Jessé de Souza}

O mito da sensualidade, cordialidade e irracionalidade dos brasileiros pode ser encontrado em autores da academia como Freyre (1990), Holanda (1976) e Faoro (1977). Souza (2015, p. 31) acredita que, ao utilizar o conceito weberiano de patrimonialismo para interpretar e legitimar a sociedade brasileira, esses pensadores teriam tornado operacional uma divisão racista entre a "gente superior das sociedades avançadas" e a "subgente" das sociedades periféricas. Ou seja, o conceito de patrimonialismo foi utilizado e compreendido no processo de construção do referido mito de forma a-histórica e sem rigor analítico.

Nomeando essa corrente que utilizou as noções de personalismo e patrimonialismo para justificar a singularidade cultural pré-moderna brasileira de culturalista, Jessé de Souza elege Gilberto Freyre como o fundador do movimento. Ao enxergar o Brasil por meio do capital social das relações sociais, o culturalismo acabou criando o mito de uma brasilidade marcada pelas virtudes ambíguas da pré-modernidade e fundaram uma "ciência conservadora" (SOUZA, 2015, p. 31), embora se pretendesse uma teoria crítica da sociedade.

2 Vianna (1999) aponta a existência de duas grandes vertentes nesse debate. Por um lado, o pensamento institucionalista que tem como representantes Faoro (1977) e Schwartzman (1998), de outro, a corrente societal que tem Fernandes (1975) e Franco (1997) como expoentes. O institucionalismo defende que o atraso brasileiro estaria relacionado com a herança patrimonial do Estado português, que teria deixado como legado um Estado independente da sociedade civil, o que teria resultado na repressão dos interesses privados e da racionalidade legal. A vertente societal, por sua vez, afirma que a ordem patrimonial é um aspecto cultural essencial das relações sociais e que ela também está presente, de forma contraditória, na constituição do Estado que é, simultaneamente, patrimonialista e racional-legal. 
Com Sérgio Buarque de Holanda (1976) e sua teoria da modernização, o culturalismo assume novas roupagens: o patrimonialismo dramatizou um falso conflito entre o mercado idealizado e o Estado corrupto. Holanda identificou a socialização brasileira a partir de traços herdados de Portugal, antitéticos à racionalidade exigida pelo capitalismo: subjetivismo, afetividade, simpatia, plasticidade. Tais características teriam formado a nação brasileira e seriam a causa de seu atraso, contrastando com povos cujas raízes religiosas eram protestantes e o trajeto que teriam seguido. A partir dessa constatação ele identificou a origem de um serviço público personalista e fundado em privilégios. O estereótipo do homem cordial brasileiro simboliza em sua obra pessoas cujas ações são guiadas pelo coração, e não pela razão. No campo da política, isso incapacita os homens de Estado de diferenciar a coisa pública da privada e faz com que o poder público se transforme em um poder familiar. O funcionário patrimonial, nascido da confusão do público e do privado, impede o surgimento do "verdadeiro Estado burocrático, em que prevalecem a especialização das funções e o esforço para se assegurarem garantias jurídicas aos cidadãos" (HOLANDA, 1976, p. 212).

Souza $(1998,2000)$ questiona a falta de uma abordagem crítica na obra de Holanda sobre a ambiguidade do legado protestante em países que sofreram essa influência religiosa. Ele também aponta as limitações de uma explicação integral do atraso brasileiro por meio da dicotomia iberismo versus protestantismo. Indo além, e aprofundando sua crítica, Souza (2015) afirma que o culturalismo de Holanda escondia as contradições sociais e naturalizava as desigualdades e exclusão social. O conceito de homem cordial de Holanda, assim como ocorria em Freyre (1990), originou um tipo de sociologia espontânea onde o mundo é percebido como produzido pelas intencionalidades dos sujeitos em interações. Ou seja, funda-se um tipo de pensamento que imagina que os juízos são subjetivos e os agentes independentes e criadores da realidade, perdendo-se assim a percepção da dimensão institucional do mundo social. Ao contrário, Souza afirma que, exceto em situações extraordinárias e passageiras como são as revoluções conduzidas por líderes carismáticos, o cotidiano é comandado por imperativos institucionais internalizados e naturalizados.

Retomando sua crítica a Freyre (1990), que postula a singularidade brasileira como herança portuguesa, Souza $(2015,2018)$ defende que tal suposição não torna o brasileiro um português. Isso porque a instituição escravidão não existiu em Portugal. O mito criado por Freyre de uma brasilidade fundada no calor humano, na sensualidade e cordialidade - que tem seu contraponto no modelo norte-americano de uma sociedade justa baseada na 
igualdade de oportunidades - possuiria o objetivo pragmático de produzir a solidariedade nacional, transformando nossa inferioridade em virtude. De forma semelhante, Holanda (1976) opõe homem cordial brasileiro ao protestante ascético dos Estados Unidos, porém, o homem cordial brasileiro é prisioneiro das paixões e, por isso, indigno de confiança e corrupto. Em suma, Souza acaba acusando Freyre e Buarque de se ancorarem em uma má sociologia que não leva em conta os contextos institucionais.

Seguindo sua crítica ao culturalismo, Souza (2018) se volta para Raymundo Faoro (1977) que buscou demonstrar as origens do patrimonialismo do Estado brasileiro e como este se estenderia à sociedade. Identificando as raízes de uma sociedade de privilégios no Brasil na formação do Estado português, na mesma linha de Holanda (1976), Faoro reafirma a ideia de uma herança ibérica influenciando o exercício político. Hegemônicas no pensamento social brasileiro (Vianna, 1999), as ideias de Faoro relacionam o atraso brasileiro com a herança patrimonial do Estado português que teria sido reforçada pela transferência da corte portuguesa para o Brasil em 1808. O principal legado português teria sido a autonomização do Estado em relação à sociedade, o que reprimiu interesses privados e comprometeu o avanço da ordem racional-legal no Brasil. Faoro (1977), argumentando que o Brasil não tinha vivenciado um passado feudal, ainda faz a aproximação do país com uma tradição política oriental que não diferenciava a esfera pública e privada. O Brasil, portanto, não é considerado pelo autor um Estado de tipo ocidental, pois o Estado teria objetivos próprios voltados para seus dirigentes. O resultado disso é o domínio patrimonialburocrático frente a um cidadão desprovido de direitos. Essa patologia de origem impediria que o capitalismo brasileiro se modernizasse completamente e vivenciasse uma modernização marcada pelo não rompimento com o passado patrimonial ${ }^{3}$. O rompimento desse oriente político, segundo Faoro, dependeria de uma reforma política que permitisse à sociedade civil manifestar livremente seus interesses sem qualquer forma de tutela estatal. Em suma, a tese central da obra de Faoro é que o patrimonialismo brasileiro é uma marca de uma ação demoníaca do Estado (Souza, 2018) e sua superação dependeria de uma reforma do próprio Estado, e não de uma reforma social. Em oposição a esse Estado autônomo que impede a liberdade dos indivíduos e a democracia, Faoro contrapõe um mercado virtuoso. Segundo Souza $(2015,2018)$, a visão de Faoro se coaduna com um tipo de liberalismo

3 Schwartzman (1988, p. 45) chamou de "neopatrimonial” esse Estado que preservaria as desigualdades do país por meio de práticas de cooptação e de restrição da livre manifestação de interesses. 
conservador que coloca de cabeça para baixo o mundo social na tentativa de comprovar um suposto patrimonialismo de Estado ${ }^{4}$.

Faoro (1977), Holanda (1976) e Freire (1990) estariam utilizando, segundo Souza (2015, 2018), o conceito weberiano de patrimonialismo de forma errônea. Sendo um tipo de dominação tradicional, o patrimonialismo weberiano é multifacetado e caracterizado por um quadro administrativo, ao contrário das dominações tradicionais gerontocráticas e patriarcais. O quadro administrativo patrimonial adquire uma relevância tão grande em Weber $(2000,2004)$ que acaba definindo um tipo de dominação racional-legal. Por outro lado, Weber também adverte que o patrimonialismo não pode ser compatibilizado de forma genérica com esferas sociais diferenciadas, sendo necessária uma contextualização histórica do conceito. Isso ocorre, inclusive, nas análises do sociólogo alemão sobre as relações entre taoísmo/confucionismo e o império chinês. Souza $(2015,2018)$ acredita que a dominação patrimonialista que controla tudo no caso brasileiro não passaria de uma ficção na medida em que uma burocracia brasileira com atuação em todo o território só se constituiu em meados do século XX. Ou seja, a maneira como o conceito de patrimonialismo foi utilizado pela sociologia brasileira não foi capaz de fazer a contextualização histórica à qual Weber se referia e acabou imputando ao Estado um mal de origem, sem qualquer vínculo com a realidade do país.

Ao relacionar a corrupção e Estado por meio da tese do patrimonialismo, a sociologia brasileira, embora tentasse se passar por crítica, estaria escamoteando a complexidade das desigualdades e injustiças do Brasil numa espécie de violência simbólica. Dito de outra forma, para Souza (2015), o culturalismo estaria substituindo o racismo científico do século XIX e legitimando a ideia de superioridade de alguns países com base em adjetivos culturais. Assim como o racismo científico, o culturalismo estaria legitimando situações de dominação ${ }^{5}$.

4 No caso brasileiro, um estamento maléfico teria tomado o Estado e estaria vampirizando a sociedade. Faoro, que fundamenta sua tese no conceito weberiano de estamento patrimonial, compara o caso português e o dos mandarins defendendo que também no Brasil havia um "estamento incrustado no Estado" (SOUZA, 2015, p. 56) que impediria a modernização.

5 A crítica deste culturalismo desligado das instituições fundamentais em Souza (2015) também é acompanhada por sua crítica o ao economicismo, que reduz o comportamento humano a estímulos econômicos. O reducionismo encetado por ambos - culturalismo e economicismo - acabariam tendo por efeito uma cegueira nas Ciências Sociais sobre o que realmente é importante na análise da reprodução simbólica do mundo social e do comportamento de cada agente. O economicismo brasileiro, cuja tradição teria se iniciado com Caio Prado Júnior (2000) que buscou associar o período colonial com a expansão do capitalismo comercial no Brasil, é analisado por Souza na obra de Francisco de Oliveira (2018). Segundo Souza (2015), a grande virtude da obra "crítica à razão dualista" (OLIVEIRA, 2018) é a percepção que o sistema capitalista como um todo é marcado 


\section{A possibilidade de superação da visão culturalista da sociologia brasileira: Florestan} Fernandes

A obra de Florestan Fernandes $(1975,1976)$ representa um avanço significativo na superação da visão culturalista da sociologia brasileira. Não obstante o viés teórico marxista presente em sua obra (FERNANDES, 2008), o autor defende que a ordem patrimonial é um aspecto cultural essencial das relações sociais brasileiras e está presente de forma contraditória na constituição do Estado ${ }^{6}$. Vianna (1999) nomina este patrimonialismo de societal, pois ele identifica a causa do atraso brasileiro no campo das relações sociais patrimoniais e de sua influência sobre o Estado, não o inverso. Fernandes (1975), indo além da perspectiva culturalista, busca destacar a particularidade com a qual a ideologia liberal foi internalizada no país no final do período colonial brasileiro. Naquele momento, essa ideologia representava muito mais a vontade de emancipação dos estamentos senhoriais da "tutela colonial" (Fernandes, 1975, p. 36) do que um desejo profundo de emancipação nacional. Após a independência teria ocorrido uma inversão e a ideologia liberal se transformou na força dinâmica da sociedade civil. Em um processo que duraria um longo tempo, essa ideologia acabou por transcender e negar a ordem senhorial-escravocrata tradicional.

A transição lenta e progressiva para uma ordem social competitiva e plural deu origem a diversos grupos sociais que, ao agir sob um sistema orientado racionalmente, desenvolviam papeis antagônicos à ordem escravocrata. Estes novos setores destacados das estruturas tradicionais passaram a coexistir e se chocar com o "sistema estamental" (FERNANDES, 1975, p. 48) escravista e patrimonialista. A lentidão e passividade com que se processava a modernização permitiu à burguesia nascente tirar vantagem da coexistência dos dois sistemas: "[a burguesia] se compromete, por igual, com tudo que lhe fosse

por uma simbiose entre o setor moderno e o atrasado, sendo que o primeiro explora o segundo. Por outro, faltaria ao economicismo de Prado a percepção de que os atores produzem consensos sociais que, além dos interesses econômicos, pressupõem um universo simbólico relacionado com o universo jurídico, emocional, a moral e político. Também faltaria a ele a compreensão de que é na reconstrução simbólica do capitalismo que determinadas classes sociais passam a agir de modo contrário a seus próprios interesses. 6 Estado aqui entendido não apenas como sociedade política, e sim "como equilíbrio entre a sociedade política e a sociedade civil (ou hegemonia de um grupo social sobre toda a sociedade nacional)". (GRAMSCI, 1972, p. 272), que é exercido por meio de organizações tidas como privadas, como a Igreja, os sindicatos, as escolas. 
vantajoso: e, para ela, era vantajoso tirar proveito dos tempos desiguais e da heterogeneidade da sociedade brasileira..." (FERNANDES, 1975, p. 204).

Nascido moderno, o Estado nacional brasileiro convivia com o patrimonialismo. Por meio desse paradoxo, o Brasil se inseriu no capitalismo mundial. $\mathrm{O}$ autor destaca que o paradigma dessa ordem contraditória é a convivência entre a agroexportação cafeeira de orientação racional-competitiva com o estilo senhorial no campo da política, em fins do século XIX. Ele ainda defende que os agentes sociais modernizantes ficaram confinados à esfera privada e se incorporaram aos círculos conservadores. Florestan vai defender que a superação desse modelo patrimonialista só poderia ocorrer com a livre manifestação daqueles que viviam sob o estatuto da dependência social que prevalecia na sociedade brasileira.

Em síntese, a análise de Fernandes busca demonstrar, nos fundamentos da formação do Estado, que os interesses dos novos grupos sociais eram muito mais vinculados à conservação do status quo que à defesa da modernização. Ao trocar o foco do Estado para a sociedade, Florestan Fernandes expõe uma sociedade agrária baseada na dominação senhorial e na dependência pessoal. Assim, ele desvenda a articulação particular entre as dimensões do público, do privado e a do Estado com a sociedade, pondo "a nu as conexões internas, vigentes na modelagem da ordem burguesa no país, entre o plano do racional-legal e o do patrimonial" (VIANNA, 1999, p. 40). Ao articular analiticamente os micro e macrofundamentos da formação do Estado brasileiro, esta perspectiva sociológica "joga uma nova luz sobre a dimensão do interesse, que deixa de ser percebido como o lugar da inovação e de resistência ao patrimonialismo, e sim da conservação do status quo" (VIANNA, 1999, p. 41). Expoente de uma visão societal do patrimonialismo, Florestan Fernandes (1975) afirma que a sociedade brasileira é marcada por uma acomodação entre tradição e modernidade. Não haveria, para ele, uma disjunção entre o moderno e o tradicional e sim uma relação dialética entre as esferas social e política ${ }^{7}$. Embora o país tenha sido incluído de forma retardatária e ambígua, Fernandes, ao contrário da visão orientalista de Faoro (1977), coloca o Brasil como parte da história ocidental. Para Jessé Souza (2018), Florestan Fernandes foi capaz de ir além da espontaneidade da sociologia brasileira que buscava interpretar as relações sociais tendo como referência a intencionalidade individual e a 
herança familiar. Florestan Fernandes sugere que a burguesia surge no país como reflexo das circunstâncias econômicas e que existiria uma anterioridade das práticas institucionais e sociais em relação ao mito patrimonialista.

Em síntese, Souza (2018) defende que a tradição dominante da sociologia brasileira interpreta a modernização da brasileira como um processo ambíguo, no qual a variável prémoderna fundamenta seu caráter incompleto. Isso explicaria a permanência do personalismo dominante na passagem do contexto patriarcal da família para o patrimonialismo de Estado. O autor defende que esse tipo de explicação é fruto de "contradições internas insolúveis" e "impede uma adequada problematização dos reais problemas que atingem esse tipo de sociedade" (SOUZA, 2018, p. 189). Por outro lado, Souza identifica na obra de Florestan Fernandes uma luz que permite vislumbrar uma concepção alternativa que dê conta dos atuais problemas das sociedades periféricas.

\begin{abstract}
A forma como Florestan percebe o aparecimento do burguês no Brasil combina perfeitamente com nossa discussão acerca da anterioridade das práticas (institucionais e sociais) em relação às ideias. O burguês, entre nós, diz ele, já surge como uma 'realidade especializada', ou seja, e agora já na nossa visão, não surge como uma criação espiritual.... Um produto econômico que, desde o começo, se constitui como resposta a estímulos econômicos concretos, sem que ocorra, pelo menos a curto e a médio prazos, uma abstração dessa circunstância para o contexto social maior (SOUZA, 2018, p. 190-191).
\end{abstract}

Ao discutir a revolução burguesa no Brasil, Fernandes (1975) aponta para o ponto essencial nesse contexto, a compreensão do padrão de civilização dominante a partir da transformação das estruturas econômicas, sociais e políticas. No caso brasileiro, o padrão dominante a partir da independência, quando ocorre o fim definitivo do pacto colonial e a estruturação do Estado, está no mundo ocidental moderno. A partir da independência, a maior parte do produto gerado passa a ser aplicado internamente e esse é o passo inicial para expansão do Estado Nacional e da construção singular de um capitalismo periférico.

A anterioridade das práticas institucionais e sociais, característica do Brasil pósindependência, tem como aspecto limitante a impossibilidade de elaboração consciente de uma visão de mundo dessas práticas. Isso não significa, no entanto, que essas práticas institucionais sejam neutras: "mercado e Estado já produzem uma visão de mundo e do ser humano contingente historicamente, que hierarquiza indivíduos e classes sociais de acordo com seus imperativos institucionais" (SOUZA, 2018, p. 192). O déficit dessa articulação significa a naturalização da desigualdade, falta de uma perspectiva de longo prazo e a incapacidade de uma compreensão aprofundada nos novos comportamentos sociais que se 
desenvolvem historicamente. Florestan Fernandes define essa falta de articulação entre a prática e as ideias como "revolução burguesa encapuzada" (FERNANDES, 1975, p. 50); uma revolução que se produz em pequena escala no cotidiano, mas que não possui uma articulação consciente de seus próprios interesses.

O ideário liberal vai representar, segundo Fernandes, os interesses da nova sociedade que se formava no Brasil no século XIX. No entanto, além de ter se difundido posteriormente às práticas que representava, o liberalismo era bastante limitado no contexto brasileiro, pois "advinha de uma posição reativa em relação à antiga ordem dominante, sendo obrigado a lutar dentro do campo de ação demarcado pelo inimigo" (SOUZA, 2018, p. 193). Exemplo dessa limitação está na posição liberal frente à abolição da escravidão: por um lado, combatiam a escravidão na defesa da economia de mercado. Por outro, os liberais acabaram firmando um compromisso "intraelite, inaugurando, a partir daí, um abandono secular de uma ralé despreparada para enfrentar as novas condições socioeconômicas" (SOUZA, 2018, p. 193).

De qualquer forma, o liberalismo explicitava os interesses da nova elite e norteava seu desempenho no mercado internacional, além de direcionar o aparelho estatal nacional após a independência. Ou seja, o ideal liberal articulou de forma incipiente todo o universo material e simbólico da sociedade nascida com a independência. Segundo Fernandes, a sociedade colonial provinciana e baseada no personalismo experimentou naquele momento uma transformação para uma sociedade nacional com relações impessoais. Nesse processo, o liberalismo foi fundamental para os sujeitos envolvidos se compreenderem. Fernandes afirma a existência de uma "silenciosa revolução socioeconômica" (FERNANDES, 1975, p. 71), que ocorre de forma parcial e incompleta dada a escassez de recursos, expressa uma modernização na qual as práticas institucionais se impõem. O liberalismo ex post facto garantiu a mediação e legitimação dos novos papeis sociais no curto prazo dessa revolução encapuzada que ocorria no Brasil de forma lenta, mas, por outro lado, foi incapaz de realizar consciente e intencionalmente, como ocorreu na Europa e Estados Unidos, as "expectativas de longo prazo para a sociedade como um todo" (SOUZA, 2018, p. 196).

\section{A Crítica de Jessé Souza a Florestan Fernandes e o aporte de Gilberto Freyre}

Apesar de considerar a análise de Fernandes (1975) sobre a modernização brasileira no século XIX fundamental na superação do culturalismo sociológico brasileiro, ao levar em conta os fatores estruturais em jogo no processo, Souza (2018) aponta deficiências no estudo 
realizado. Em especial, faltaria a Florestan Fernandes considerar a "dimensão da ação social consubstanciada na tematização dos grupos e classes suportes do processo de modernização" (SOUZA, 2018, p. 196). Existiria na obra do autor um hiato entre a consolidação da estrutura do Estado no início do século XIX que originou o processo de mudança social e a tematização dos agentes da modernização. Ele considera os agentes da modernização os fazendeiros de café do Oeste paulista e os imigrantes italianos que só chegam ao Brasil em fins do século XIX. Ou seja, ele desconsidera o processo de modernização que se inicia no Rio de Janeiro no início do século XIX.

Segundo Souza, esse hiato é explicado pelo fato de Fernandes interpretar a modernização periférica brasileira a partir do arcabouço patrimonialista que enfatiza a excepcionalidade paulista. Assim como Holanda (1976) e Faoro (1977), Fernandes (1975) teria sido incapaz de abandonar essa corrente interpretativa. Nesse tipo de visão, a modernização é um processo endógeno, São Paulo é como uma Inglaterra dos trópicos e o bandeirante um embrião do capitalista empreendedor, em oposição a um país atrasado, personalista e corrupto. Em função da não consideração por parte de Fernandes da modernização exógena que se dá nos centros urbanos brasileiros a partir de 1808, Souza propõe uma complementação das ideias desse pensador com as de Gilberto Freyre (1990).

Em "Sobrados e mocambos", escrito em 1936, Freyre aborda a reeuropeização da vida urbana brasileira na primeira metade do século XIX pari passu à decadência lenta da cultura rural patriarcal. Enquanto Fernandes (1975) considerava o ponto de inflexão dessa transformação o rompimento político com Portugal em 1822, Freyre aponta para a abertura dos portos em 1808 como um marco mais significativo. $\mathrm{Na}$ verdade, esses dois acontecimentos são fundamentais para ilustrar a consolidação no país do Estado e do mercado, práticas institucionais fundamentais da modernidade.

A vinda da corte, especificamente, significou um controle fiscal e político mais intenso da colônia, a criação de uma série de serviços e melhoramentos sociais, um aumento da troca de mercadorias e a entrada de novos personagens na sociedade brasileira (comerciantes, manufatureiros, mecânicos, excursionistas europeus, entre outros). Esse é o momento no qual a vida urbana e o Estado se afirmam sobre o mundo rural patriarcal. Paulatinamente, o senhor de terras se vê ameaçado pelo comerciante, pelo prestamista, pelo financista, pelo Estado e por seus agentes. Em suma, mercado e Estado, ainda que de forma ambígua, vão substituindo aos poucos o poder pessoal pelas instituições impessoais importadas. Esse processo, apesar de evidente, não foi linear. A interpenetração de interesses 
urbanos e rurais fez com que houvessem negociações eivadas de avanços e retrocessos, tanto no espaço público como no privado ${ }^{8}$.

Freyre (1990) afirma que hábitos, costumes, valores e normas foram transformados durante essa reeuropeização a partir de 1808. Foi introduzido, então, um novo mundo material e simbólico que valorizava elementos ocidentais e individualistas oriundos da Europa burguesa. Surge naquele momento o núcleo da ideia de modernidade na sociedade brasileira. Essa revolução "de cima para baixo" (SOUZA, 2018, p. 205) envolveu todos os estratos sociais, alterando a posição e o prestígio desses segmentos e incluindo novos elementos de diferenciação. Em especial, o conhecimento e o talento individual passaram a ser valorizados e se tornaram definidores da nova hierarquia social e da possiblidade de mobilidade social. Para Freyre (1990), o mulato habilidoso era o suporte dessa democratização que ocorria na sociedade. Do lado do mercado, por sua vez, as transformações seguiam a "lógica de baixo para cima" (SOUZA, 2018, p. 206) por meio da valorização do trabalho manual considerados na sociedade anterior como indignos. Em suma, a nova sociedade valorizava o elemento médio que possuía o capital cultural ao invés do senhor e do escravo:

Na nova sociedade nascente, na visão de Freyre, são as antigas posições polares que perdem peso relativo, e esses indivíduos, quase sempre mestiços, sem outra fonte de riqueza que não sua habilidade e disposição de aprender os novos ofícios mecânicos, quase sempre como aprendizes de mestres e artesãos europeus, passaram a formar o elemento mais tipicamente burguês daquela sociedade em mudança: o elemento médio, sob a forma de uma nova meia-raça (SOUZA, 2018, p. 206).

Ao perceber o processo de modernização exógena que altera todas as relações sociais brasileiras no início do século XIX, embora mantendo a ideia de continuidade cultural portuguesa, a obra de Freyre (1990) complementa a análise de Fernandes. O estilo narrativo do autor recupera a realidade progressiva dos princípios, dos estilos de vida e do cotidiano da época que foram secundarizadas pela análise abstrata de Fernandes. Este último, por outro lado, foi capaz de perceber, ao contrário de Freyre, a "profundidade da relação entre estrutura e a gente envolvida no processo de modernização" (SOUZA, 2018, p. 207).

8 Freyre (1990) descreve em "Sobrados e mocambos" o lento declínio do poder do patriarca sobre a mulher e seus filhos no âmbito doméstico. A entronização do amor romântico em fins do século XIX e a valorização de jovens diplomados para ocupar os cargos de Estado, por exemplo, abalam o poder patriarcal. No espaço público essas mudanças foram mais enfáticas como demonstra o autor utilizando-se da metáfora do sobrado e da rua: o sobrado como prolongamento do poder senhorial, a rua como representação primitiva do espaço público e desprezada pelos senhores. Essa oposição sobrado-rua acaba com a unidade orgânica da relação casa grande-senzala aprofundando os conflitos sociais. 
O hiato anteriormente referido na obra de Fernandes entre o catalisador da mudança (a independência) e os grupos que dão suporte a ele (fazendeiros do café e imigrantes italianos) é explicado por Souza pela secundarização do aspecto ação social em sua obra. Por isso,

a consideração combinada da visão desses dois grandes pensadores, talvez os dois maiores que o país já produziu, pode, a meus olhos, desde que superadas suas unilateralidades recíprocas, nos propiciar uma adequada visão do período considerado como um todo (SOUZA, 2018, p. 207).

Souza nomina de processo modernizador da nova periferia o que ocorreu no Brasil a partir de 1808. Essa modernização periférica ocorreu devido ao influxo de crescimento do capitalismo industrial europeu que traslada práticas institucionais marcadas pela impessoalidade, ao contrário do que ocorreu com a expansão do capitalismo comercial que não alterou as estruturas tradicionais e personalistas. A visão de mundo trazida pelas novas práticas institucionais passa, então, a construir e a guiar as condutas de vida na sociedade brasileira que antes era regida "por uma cultura material e simbólica rasteira e primitiva" (SOUZA, 2018, p. 208). Esse processo modernizador é lento e pouco homogêneo em todas as regiões. A vitória definitiva dessa modernização periférica no país exigirá, além do influxo exógeno, um influxo endógeno resultado da "formulação consciente e refletida de um projeto modernizador autônomo e nacional" (SOUZA, 2018, p. 209).

A formulação consciente desse projeto modernizador, autônomo e nacional só ocorrerá com a Revolução de 1930 (VIANNA, 1976). Apesar de apropriado por uma elite tradicional oligárquica, a heterogênea aliança liberal que ascende ao poder naquele momento defendia a diversificação do aparato produtivo e a ampliação da participação política. $O$ fundamental era permitir a participação de setores até então marginalizados elevando o patamar da reprodução do Estado e do mercado. Apesar de não ter havido a participação efetiva da nascente burguesia industrial do processo revolucionário de 1930, o Estado toma, de forma consciente, o caminho da industrialização.

Viana (1976) ainda defende a tese de um caminho prussiano de modernização no Brasil por meio de uma associação no Estado da elite tradicionalista latifundiária, que inviabilizou a reforma agrária e a extensão dos direitos trabalhistas no campo, com setores urbanos emergentes. Permaneciam assim as relações primitivas nas regiões atrasadas inibindo-se demandas mais plurais na esfera pública ao mesmo tempo em que ocorria o esforço modernizante do capitalismo. 
Esse "unitarismo organicista" (VIANNA, 1976, p. 159), em oposição ao liberalismo formal que prevalecia anteriormente, era uma ideologia política avessa a interesses particulares e terá seu ideal de ação no sistema corporativista. Enfatizando a organicidade e a grandeza da nação, o Estado promove o consenso entre as classes dominantes e setores médios urbanos ascendentes, ao mesmo tempo em que reprime e faz concessões aos setores subalternos. Não havia, segundo Vianna, um pacto com as classes subalternas. Até 1935, a estratégia do Estado foi a repressão e a desmobilização. A partir daí, essas classes foram manipuladas e cooptadas. Ou seja, primeiro o corporativismo acabou com as organizações independentes. Posteriormente, estas organizações passam a ter uma sindicalização compulsória se o trabalhador quisesse ter a garantia dos direitos trabalhistas e previdenciários. Impõe-se, assim, uma estrutura corporativa de um Estado autoritário modernizante.

No Brasil após a Revolução de 1930 apenas os empresários não se submeteram à burocracia corporativista, o que os tornavam os únicos agentes livres de mercado. Apesar de não terem sido agentes ativos da Revolução, essa burguesia industrial se torna a fração dominante entre as classes dirigentes, isto porque o desenvolvimento do mercado interno representava o interesse dessas classes. Em um primeiro momento os industriais apoiaram o Estado autoritário e repudiaram as leis trabalhistas, porém logo perceberam que suas pretensões hegemônicas exigiam um pacto federativo que caminhava "para um compromisso a partir da aceitação da legislação social” (SOUZA, 2018, p. 215).

A análise de Vianna (1976) sobre a relação entre política e sociedade representa um exemplo explícito da crítica ao "intencionalismo que reduz a complexidade social aos motivos conscientes dos sujeitos envolvidos" (SOUZA, 2018, p. 209). A obra "Liberalismo e sindicato no Brasil" (Vianna, 1976) seria uma continuidade da "Revolução burguesa" de Florestan Fernandes (1975) na medida em que ambos os autores percebem a modernização brasileira como uma "revolução encapuzada" (FERNANDES, 1975, p. 50) ou, como prefere Vianna (1997), uma "revolução passiva". As teses de Fernandes e Vianna, portanto, estariam de acordo com a ideia de Souza (2018) de que no processo modernizador brasileiro as práticas institucionais e sociais são anteriores às ideias.

As reflexões de Vianna $(1976,1997)$ ainda permitem uma discussão acerca dos limites e possibilidades da expansão da ordem burguesa no Brasil tendo o liberalismo como ideologia. Fernandes (1975) defendeu a ideia que o liberalismo permitiu uma expansão negociada e a legitimação da ordem burguesa no século XIX no contexto intraelite No 
entanto, no início do século XX, essa ordem elitista se encontrava em crise. Vianna (1976) afirma que, no período que antecedeu a Revolução de 1930, o liberalismo formal, distante dos ideais de uma ordem impessoal e legal, estava associado aos interesses da elite agrária exportadora e de seus interesses federalistas descentralizadores que sustentavam e eram sustentados pela política do café-com-leite. Essa ordem liberal e federalista demonstrava-se fragilizada na década de 1920: setores populares (operários), médios (classe média urbana e setores militares), a nascente burguesia industrial e os setores agrários ligados ao mercado interno demonstravam sua insatisfação na medida em que se sentiam marginalizados pelo jogo político.

De certo modo, foi a própria revitalização social, ainda que dentro de limites econômicos e políticos rígidos, fruto da expansão do setor exportador, que liberou forças impossíveis de controlar dentro de uma camisa de força política e socialmente tão excludente (SOUZA, 2018, p. 211).

A oligarquia dissidente que assumiu o poder com a Revolução de 1930 se torna, então, responsável por uma modernização que se origina na periferia para o centro do sistema (Vianna, 1976). Conforme afirmado anteriormente, será a heterogênea aliança liberal que se apossa do Estado, apesar de não contar com a participação efetiva da incipiente burguesia industrial, que garante a participação de setores marginalizados na elevação do patamar de reprodução do Estado e do mercado tomando o rumo da industrialização. A tese de Vianna sobre a modernização prussiana no Brasil se constrói a partir dessa configuração.

Os nossos junkers caboclos viriam de representações políticas de regiões dominadas pelo latifúndio, o que iria implicar preservação do monopólio da terra, inviabilização da reforma agrária e exclusão dos trabalhadores rurais dos benefícios sociais e trabalhistas (VIANNA, 1976, p. 171).

Associados a setores urbanos emergentes, esses junkers caboclos deram origem a um bem sucedido Estado de dimensão universalista e modernizadora, se consideradas as condições anteriores de participação social e bases materiais do capitalismo brasileiro. Na prática, isso significou a "permanência de relações primitivas nas regiões atrasadas (especialmente Norte e Nordeste) e a inibição das demandas mais plurais na esfera pública da Primeira República” (VIANNA, 1976, p. 172).

O período inaugurado em 1930 constrói, portanto, um "unitarismo organicista" (VIANNA, 1976, p. 159) que escamoteia os conflitos e é avesso a interesses particulares, em especial, os populares. O espírito corporativista desse novo Estado conjuga os interesses consensuais de frações das classes dominantes e setores médios ascendentes, ao mesmo tempo em que reprime e faz concessões às classes subalternas. Envolve todo esse aparato de 
dominação uma ideologia fundada na "organicidade, unidade e grandeza nacional" (SOUZA, 2018, p. 214).

Essa estrutura corporativa do Estado era destinada a abranger tanto trabalhadores quanto empresários na sua disciplina, mas acaba por converter-se num Estado autoritário modernizante. Os empresários, ao mesmo tempo em que legitimam o caráter repressivo do Estado, acabam por não se submeter à burocracia, repudiam as leis protetivas dos trabalhadores e se tornam os únicos agentes livres do mercado. Nesse processo, os industriais, mesmo tendo participado ativamente da Revolução, se tornam a fração dominante entre as classes dirigentes, pois do seu sucesso dependia o fortalecimento do mercado interno que era o fundamento do "novo pacto federativo" (Vianna, 1976, p. 159). Aceita a hegemonia dessa burguesia industrial, estavam abertos os caminhos para "um compromisso a partir da aceitação da legislação social" (SOUZA, 2018, p. 215). Esse Estado autoritário e modernizador consolidado em 1930 e assumido pelo setor industrial coloca em outro patamar a modernização brasileira iniciada em 1808 que havia, até então, sido comandada pelo surto urbanizador e comercial.

\section{Conclusão}

Souza (1999) e Vianna (1998, 2000) podem ser situados entre os intelectuais revisionistas das interpretações que tentaram utilizar a matriz weberiana para analisar a formação da sociedade brasileira. As críticas que ambos elaboram ao arcabouço teórico patrimonialista brasileiro explicitam as fragilidades analíticas desse modelo que buscava situar e explicar o Brasil como país periférico marcado pelo amálgama da dominação tradicional/racional e associaram o atraso em relação ao centro capitalista com a herança patrimonialista ibérica. Tal modelo, segundo seus críticos, teria mascarado formas despóticas e atrasadas da política brasileira ao longo do tempo.

Centrando sua crítica em Faoro (1977) e Schwartzman (1988), Vianna (1999) contesta a justificação do atraso brasileiro por meio do conceito de patrimonialismo ibérico de características orientais que está presente na obra desses autores. Segundo Vianna, essa teoria do atraso impossibilitaria a soberania democrática, pois o Estado estaria sempre interessado na realização dos objetivos dos seus próprios dirigentes. Estaríamos, portanto, fadados a "uma modalidade patológica de acesso ao moderno" (1999, p. 176). A crítica de Vianna a esse modelo é centrada na suposta organização societária oriental do Brasil que não havia tido um passado feudal. O principal problema nessa interpretação se vincula ao 
escamoteamento da realidade do país a partir de um determinismo e generalização históricos. Determinadas experiências particulares são perdidas nesse tipo de análise, em especial, o paradoxo da convivência no país entre o mundo rural, a dependência pessoal, a administração racional e a patrimonialista. Outra crítica apontada por Vianna é que a análise dos problemas nacionais pelo viés do atraso é a convivência, no mesmo território, entre atraso e modernidade. Com esse tipo de análise weberiana, a história brasileira fica restrita à "desigualdade social, a injusta distribuição de renda, a hierarquia social verticalmente rígida, as formas autoritárias de poder, a democracia frágil e, sobretudo, a persistência do patrimonialismo" (COUTO, 2016, p. 107).

Se inspirando em Franco (1997), Vianna (1999) defende que a saída para reverter o atraso do país é a produção de seres sociais autônomos e com identidade definida. No entanto, isso dependeria de dois fatores: de um lado, da erradicação do patrimonialismo societal que foi preservado durante a modernização da sociedade brasileira e, de outro lado, de se colocar um fim à instrumentalização da esfera pública pela privada. Essa visão, embora não abandone a ideia de patrimonialismo como causa do atraso brasileiro, deixa de lado a explicação orientalista e afirma a coexistência paradoxal no Brasil de uma ordem burocrática racional-legal e do poder local dos senhores de terra, o que resultaria na não diferenciação entre o público e o privado.

Jessé Souza (1998, 2000), por sua vez, qualifica de inautêntica e exagerada a matriz weberiana institucional de interpretação da história do Brasil. Ele questiona a falta de uma abordagem crítica na obra de Holanda (1976) sobre a ambiguidade do legado protestante e aponta as limitações de uma explicação integral do atraso brasileiro por meio da dicotomia iberismo versus protestantismo. Na obra de Faoro (1977), Souza diz que o objetivo do autor é provar que o patrimonialismo do Estado coagiria a liberdade de empreendimento no Brasil e que a irracionalidade estamental estaria em choque com a racionalidade empreendedora. Souza (2000) acusa Faoro de produzir uma obra a-histórica, ao contrário do patrimonialismo weberiano, ao partir da ideia pré-concebida de que "sempre que temos Estado, temos um estamento que o controla em nome de interesses próprios, impedindo o florescimento de uma sociedade civil livre e empreendedora" (SOUZA, 2000, p. 172). Sobre a afirmação de Schwartzman (1988) que aponta a existência de uma realidade distinta do empreendedor de São Paulo que não teria recebido o influxo patrimonial, Souza (1998) defende ser uma ilusão essa análise, pois o desenvolvimento desigual deste estado deve levar em conta, em especial, o trabalho do imigrante. 
No entanto, como afirmado ao longo do texto, a contundência da crítica de Souza ao paradigma culturalista, enxerga uma exceção na obra de Florestan Fernandes (1975). Indo além da espontaneidade da sociologia brasileira que buscava interpretar as relações sociais e tendo como referência a intencionalidade individual e a herança portuguesa, Florestan percebe que a burguesia surge no país como reflexo das circunstâncias econômicas e que existiria uma anterioridade das práticas societais em relação ao mito patrimonialista institucional.

Ao invés de um processo ambíguo de modernização no Brasil onde a variável prémoderna explica seu caráter incompleto, Souza (1998, 2000), assim como Vianna (1999), buscam uma concepção alternativa que dê conta dos atuais problemas das sociedades periféricas. Nesse sentido, eles clamam a necessidade de uma reanálise das teorias sociais brasileiras fundadas na dicotomia atraso versus moderno e que, quase sempre, identificaram o patrimonialismo do Estado como entrave à modernização e tomaram como autoevidentes os conceitos de atraso e modernidade. Ao mesmo tempo, os críticos do paradigma patrimonialista estão abertos à contribuição significativa que representantes desse modelo analítico podem aportar, em especial, na vertente do patrimonialismo societal (FERNANDES, 1975 e FRANCO, 1997), para compreensão dos aspectos constitutivos da formação histórica brasileira.

O que fica patente na análise realizada pelos críticos do paradigma patrimonialista são as dificuldades e possiblidades para implantação de um projeto de democracia liberal em um país em transformação como o Brasil. As virtudes do mercado sugeridas por Faoro (1977) dificilmente seriam suficientes para garantir a liberdade dos indivíduos e a democracia. Como afirma Souza (2018), isso apenas perpetuaria um tipo de liberalismo conservador de privilégios. Historicamente, os grupos privados se apossaram do Estado para fazer valer seus interesses e utilizaram-se dos laços de dependência pessoal para aprofundar a confusão entre o público e o privado. Nada indica que a diminuição do papel do Estado na condução da economia ou das questões sociais significaria que os interesses privados beneficiariam a sociedade como um todo. Ao contrário, as elites brasileiras sempre demonstraram um descaso com as questões de equidade e justiça (YAZBEK, 1993). Partindo do princípio que uma modernização mediada pelo arcaico apenas recria a herança escravista e patrimonialista, é defendida a necessidade de rompimento com a nossa formação originária. $\mathrm{Na}$ prática, isso significa o questionamento do liberalismo formal e do patrimonialismo que privilegia as elites e a construção, por seres sociais autônomos e com 
identidade definida (VIANNA, 1999), de uma cultura garantidora de direitos sociais para a maior parte da população.

\section{Referências}

BAQUERO, M. "Cultura política participativa e desconsolidação democrática: reflexões sobre o Brasil contemporâneo". São Paulo em Perspectiva, v. 15, n. 4, São Paulo, 2001, p. $98-104$.

BEHRING, E. R. e BOSCHETTI, I. S. Política Social: fundamentos e história. $2^{\mathrm{a}}$ ed., São Paulo: Cortez, 2007.

COUTO, Elvis Paulo. “As Raízes do Patrimonialismo de Estado no Brasil”. Revista

Habitus: Revista da Graduação em Ciências Sociais do IFCS/UFRJ, v. 14, n. 1, Rio de Janeiro, 2016, p. 100-112.

FAORO, Raymundo. Os donos do poder: formação do patronato político brasileiro. $4^{\mathrm{a}}$ ed., Porto Alegre: Globo, 1977.

FREYRE, Gilberto (1936). Sobrados e mocambos: decadência do patriarcado rural e desenvolvimento do urbano. Rio de Janeiro: Record, 1990.

FERNANDES, Florestan. A Revolução Burguesa no Brasil: ensaio de interpretação sociológica. Rio de Janeiro: Zahar, 1975.

FERNANDES, Florestan. A sociologia numa era de revolução social. Rio de Janeiro: Zahar, 1976.

FERNANDES, Florestan. "Florestan Fernandes". Entrevista ao site orientação marxista realizada por Paulo Tarso Venceslau, 2008. Disponível em:

<http://orientacaomarxista.blogspot.com/2008/09/florestanfernandes.html>. Acesso em 28 de Nov. de 2018.

FRANCO, Maria Silvia de Carvalho. Homens Livres na Ordem Escravocrata. São Paulo: UNESP, 1997.

GRAMSCI, A. Los intelectuales y la organización de La cultura. Buenos Aires: Nueva Visión, 1972.

HOLANDA, Sérgio Buarque de. Raízes do Brasil. 9. ed. Rio de Janeiro: José Olympio, 1976.

IAMAMOTO, M. V. O Serviço Social na Contemporaneidade: trabalho e formação profissional. 10ª ed., São Paulo: Cortez, 2006. 
OLIVEIRA, Francisco de. Crítica à Razão Dualista / O Ornitorrinco. São Paulo: Boitempo, 2018.

PAULA, J. A. Adeus ao desenvolvimento: a opção do governo Lula. Belo Horizonte: Autêntica, 2005.

PRADO JR., Caio. Formação do Brasil contemporâneo. São Paulo: Brasiliense, 2000. SCHWARTZMAN, Simon. Bases do autoritarismo brasileiro. $3^{\text {a }}$ ed., Rio de Janeiro: Campus, 1988.

SOUZA, Jessé. "A ética protestante e a ideologia do atraso brasileiro". Revista brasileira de ciências sociais, v. 13, n. 38, 1998. Disponível em: < http://www.scielo.br/pdf/rbcsoc/v13n38/38jesst.pdf>. Acesso em: 10/08/2018. SOUZA, Jessé. A modernização seletiva: uma reinterpretação do dilema brasileiro. Brasília: Editora Universidade de Brasília, 2000.

SOUZA, Jessé. Subcidadania brasileira. Para entender o país além do jeitinho brasileiro. São Paulo: LeYa, 2018.

SOUZA, Jessé. A tolice da inteligência brasileira ou como o país se deixa manipular pela elite. São Paulo: LeYa, 2015.

VIANNA, Luiz Werneck. Liberalismo e sindicato no Brasil. Rio de Janeiro: Paz e Terra, 1976.

VIANNA, Luíz Werneck. A revolução passiva: iberismo e americanismo no Brasil. Rio de Janeiro: Revan, 1997.

VIANNA, Luiz Werneck. "Weber e a interpretação do Brasil”. In: SOUZA, Jessé (org.). O malandro e o protestante: a tese weberiana e a singularidade cultural brasileira. Brasília: Editora Universidade de Brasília, 1999, p. 173-193.

WEBER, Max. Economia e sociedade. v. 1. Brasília: Editora UnB, 2000.

WEBER, Max. Economia e sociedade. v. 2. Brasília: Editora UnB, 2004.

YAZBEK, M. C. Classes Subalternas e Assistência social. São Paulo: Cortez, 1993. 